\title{
The design and application of the solar energy fan
}

\author{
Fengjun $\mathrm{Wei}^{1}$, Fude Wang ${ }^{2 *}$ \\ ${ }^{1-2}$ Shandong Huayu Univeisity of Technology.
}

\begin{abstract}
This article introduces a solar fan device, which can alleviate the overheating phenomenon of solar water heating system, and can be installed on the building as a component of the building, which can ventilate the building and improve the air quality of the building. introduced its design principle and structure. Taking the actual project as an example, the application and test results of the solar scalp were explained, which provided certain practical experience for the promotion and application of the solar scalp.
\end{abstract}

\section{Introduction}

As the world attaches great importance to the use of renewable energy, solar water heating systems have become popular, and solar energy systems can be applied in various ways ${ }^{[1]}$, but the principle is to use solar collectors to collect sunlight energy and then convert it into the required energy, so as to achieve the purpose of convenient use. However, because solar energy is greatly affected by environmental factors such as seasons and climate, the energy provided by the solar energy system in certain periods of time is insufficient, and sometimes the energy provided by the system will be excessive. Realistic solar energy systems generally use winter conditions as the design conditions (different situations depending on energy use) ${ }^{[2]}$ to ensure the energy demand in winter, and such a design may cause the solar energy supply in other seasons to exceed the demand, lead to excess heat in the system; some solar water heating systems are only used in summer and winter, so there must be a large amount of energy surplus in spring and autumn ${ }^{[3]}$. For example, solar cooling and heating projects have a large demand for heat energy, so the system is installed with heat collectors There are many, but cooling and heating projects are only used in summer and winter. Even if bathing consumes part of the heat in spring and autumn, there will still be a lot of excess heat. If the excess heat is not treated in time, it will bring serious harm to the solar energy system, and the current energy storage technology is not yet mature. This contradiction between supply and demand is particularly prominent in the design of solar air conditioning systems. This article introduces a new type of product - solar wind turbine, which is used as a heat sink for solar water heating systems. It can not only solve the problem of system overheating, but also replace the building with fresh air and improve the air quality in the living and working environment.

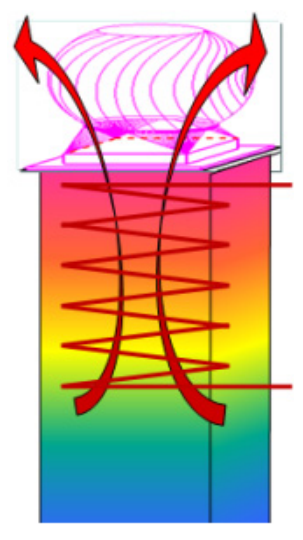

Figure 1: Schematic

\section{The working principle of the solar energy winder}

The solar fan is a heat dissipation element of the solar system, and it is also a ventilation element of the building. The design adopts the principle of buoyancy effect, that is: the hot water stored in the water tank by the solar hot water system is circulated by the circulating pump to make the hot waterAfter passing through the finned coil in the solar fan, it fully dissipates heat and heats the air around the coil. After the air is heated, the volume expands and the density decreases, and the air starts to flow upwards, causing the pressure around the coil to decrease (compared to indoors), Under the action of the pressure difference, the indoor air starts to flow outwards, so that the solar fan can play the role of replacing the indoor fresh air.

The solar energy fan is a product designed to solve the overheating of the solar energy system. When the solar energy system has seasonal overheating conditions, the solar energy fan will be used as the energy-consuming equipment of the system to consume the excess heat in the solar water heating system. Ensure the normal operation of the system. However, the heat

*Corresponding author's e-mail: nyyjzgcxy@huayu.edu.cn; wfd87120@126.com. 
that has already been dissipated in vain will inevitably cause great waste. Therefore, this kind of radiator is made into a building's fresh air device to replace the building with fresh air ${ }^{[4]}$ and improve the comprehensive utilization rate of the solar water heating system. Mainly suitable for solar air-conditioning systems and residential solar water heating systems for periodic short-term residence.

\section{3 main components of the solar wind turbine}

The main design idea of the solar winder is to alleviate the overheating problem of seasonal solar water heating system, and at the same time improve the effect of fresh air in the building environment. Its main components are air ducts, coil heat exchangers and unpowered hoods. The heat source is solar energy system. The heat generated, the cold source is the flowable air in the air extractor, and the exhaust air volume of the air extractor is adjusted by adjusting the temperature and flow rate of the heat source.

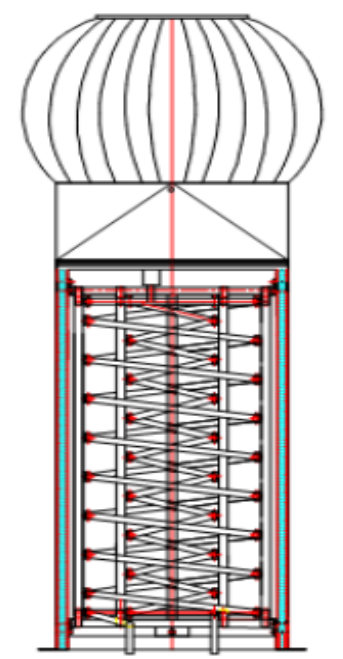

Figure 2: Structure diagram

\subsection{Air duct and coil heat exchanger}

The coil heat exchanger includes an inner coil and an outer coil that are connected to each other. The inner coil is placed in the middle of the air pipe, the outer coil is sleeved outside the inner coil, and the inner and outer coils are in the middle of the air pipe. The upper end is connected. The inner coil is provided with a water inlet at the lower end of the air pipe. The water inlet is connected to the water supply end of the solar hot water system. The outer coil is provided with a water outlet at the lower end of the air pipe. The backwater end of the water system is connected.

The coil heat exchanger is fixed in the air duct and connected with the water supply end and the return water end of the solar hot water system to form a heat dissipation cycle. After the excess heat in the solar hot water system is dissipated by the heat exchanger, it is discharged through the air duct. At the same time, this heat is used as the power of the air duct to increase the exhaust air volume of the duct.

\subsection{Unpowered hood}

The unpowered hood is fixed to the upper end of the wind pipe through a transition piece ${ }^{[5]}$. The cross section of the wind pipe is a square structure conforming to the building modulus. The connection cross section of the unpowered hood is a circular structure, so one end of the transition piece is The cross-sectional structure of the air duct is a square structure, and the other end is a circular structure that is consistent with the cross-sectional structure of the unpowered hood. The combination with the unpowered hood can form a functional complementarity, that is to say, in the season when the solar water heating system is overheated, the exhaust device can still exhaust a small amount of air through the unpowered hood, while the solar water heating system is overheated. In season, the unpowered hood plays a role in fueling the flames.

\section{Engineering examples of solar energy wind turbines}

\subsection{Introduction of engineering examples}

The Zero Carbon Pavilion is located in the Beijing Olympic Forest Park. The building is a one-story building. The solar thermal system is combined with an adsorption air-conditioning unit to cool the building. At the same time, it also provides life to two bathing rooms. For hot water supply, considering that the solar hot water system in other seasons except summer cooling still has excess heat in addition to bathing, two solar energy fans have been installed in the three bathrooms of the building, which have two functions. First, the solar hot water system activates the solar fan during the overheating season, which can play a role in dissipating the solar system; second, through the solar fan's role of pulling out the wind, it can replace the building with fresh air and prevent the stale air in the bathroom. Pollution of the indoor environment.

As shown in Figure 3, two solar wind turbines are installed on the roof of the building, one of which is 500 type: $500 \mathrm{~mm} \times 500 \mathrm{~mm}$ cross-section and the height is $1000 \mathrm{~mm}$; the other is 300 type: $300 \mathrm{~mm} \times 300 \mathrm{~mm}$ cross-section and the height is $500 \mathrm{~mm}$, The installation foundation is $500 \mathrm{~mm}$ higher than the roof, the outer shell of the solar winder is a composite board with a glass fiber reinforced plastic sandwiched with thermal insulation material, and the inner coil is a 6-point copper tube, of which the 500 type is a spiral coil with fins on the coil, The coil tube is $50 \mathrm{~mm}$ away from the shell, the length of the coil tube is $12 \mathrm{~m}$, and the other 300 type heat exchanger has 6-point upper and lower straight pipes in parallel, the heat exchanger tube length is $15 \mathrm{~m}$, the distribution is relatively in the middle of the play and extends from the foundation to the building $500 \mathrm{~mm}$. The solar wind extractor is connected to the building through expansion bolt sealant. 


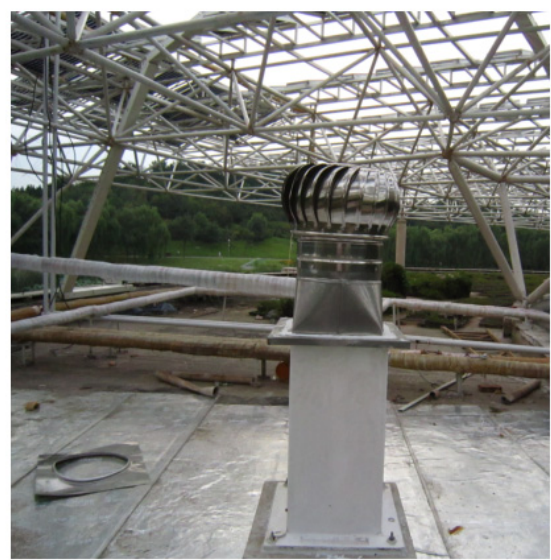

\subsection{Test plan and data analysis:}

After the project was installed and debugged, the system was tested. The test test uses a data acquisition instrument to automatically collect data, the touch Screen computer displays the test curve on-site, and uses 7 temperature sensors, two wind speed and temperature sensors and the system's own turbine flowmeter for data testing. The specific test plan is shown in Figure4.

Figure 3: Solar wind extractor on site of Beijing Zero Carbon

Hall

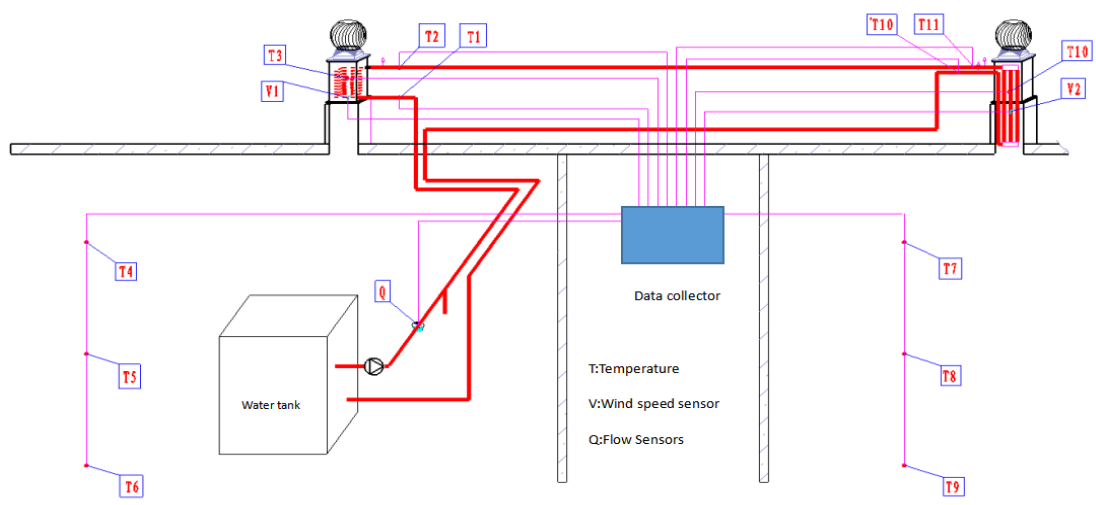

Figure 4: The test plan of the solar wind extractor

\subsubsection{Calculation of exhaust air volume}

$$
\mathrm{Q}=3600 \times \mathrm{V} \times \mathrm{S}
$$

In the formula: Q----- is the air volume in the solar fan $\mathrm{m}^{3} / \mathrm{h}$

$\mathrm{V}$-------is the wind speed in the solar wind turbine $\mathrm{m} / \mathrm{s}$

S------- is the cross-sectional area of the solar winder $\mathrm{m}^{2}$

\subsubsection{Calculation of heat dissipation capacity}

$$
\mathrm{P}=\frac{\mathrm{C} \times \mathrm{M} \times \Delta \mathrm{T} \times 10^{6}}{3600}
$$

In the formula: P----heat dissipation power $\mathrm{W}$

C-----specific heat capacity $\mathrm{kJ} /\left(\mathrm{kg} \cdot{ }^{\circ} \mathrm{C}\right)$

M-----mass flow $\mathrm{T} / \mathrm{h}$

$\Delta \mathrm{T}$---Inlet and outlet temperature difference ${ }^{\circ} \mathrm{C}$

After the solar ventilating device is operating normally, conduct a test experiment on it. According to the test data, obtain the inlet and outlet temperature of the coil tube, the temperature of the ventilator, the exhaust air volume and the wind speed of the ventilator when the solar ventilator is working normally. And the heat dissipation power of the air puller, the specific results are shown in Figure 5, Figure 6 and Figure 7.

\section{Conclusion}

1. According to the test data of the solar winder, it is concluded that the ventilation range of the solar winder during normal operation is between $2000 \mathrm{~m} 3 / \mathrm{h} \sim 2500 \mathrm{~m} 3 / \mathrm{h}$; the heat dissipation capacity is between $7 \mathrm{kw} \sim 12 \mathrm{kw}$.

2.The main components of the solar winder are composed of air pipes, coil heat exchangers and unpowered hoods; the heat source of the winder is the heat collection and storage device of the solar water heating system, and the cold source is the indoor heat source of the building. Air, by adjusting the temperature and flow rate of the heat source, the exhaust air volume of the solar fan can be adjusted.

3.Practice has proved that the solar energy fan plays a positive role in alleviating the overheating of the solar water heating system and adjusting the indoor air quality. The promotion and application of solar energy fans will inevitably promote the popularization of solar cooling and heating systems. 


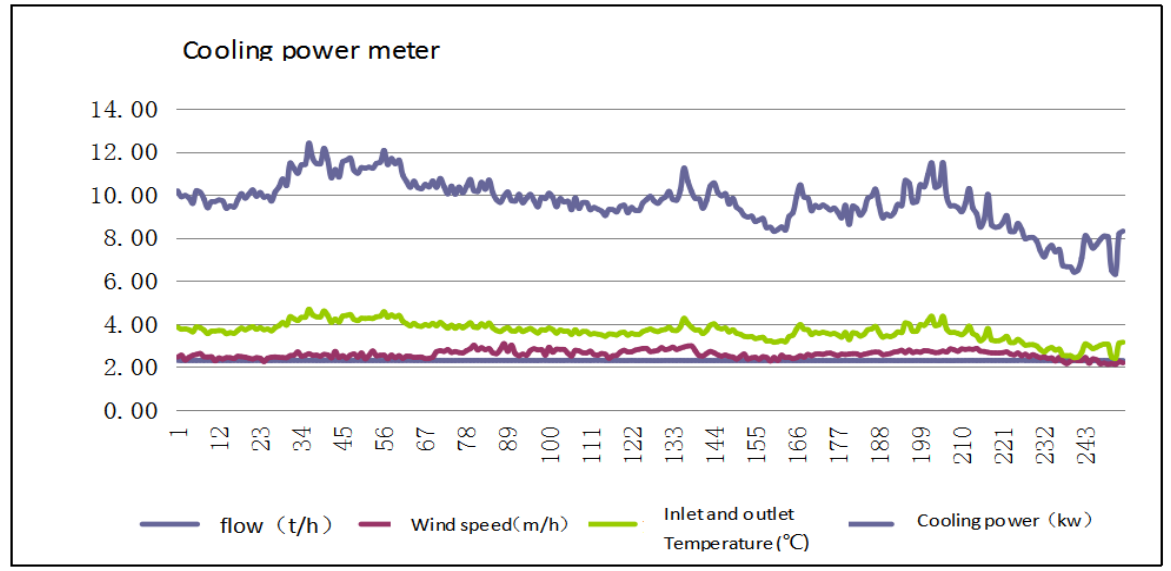

Figure 5: Cooling power

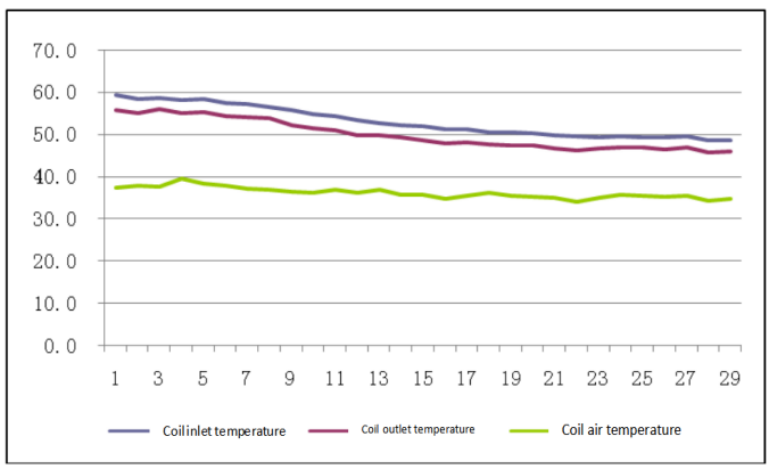

Figure 6: Water supply temperature and air duct temperature

\section{Acknowledgments}

In the process of writing this article, relying on the platform of the Building Energy-saving Engineering Technology Research and Development Center of Dezhou City, Shandong Province, and referring to many documents, I would like to express my gratitude to the original authors of the references!

\section{References}

1. Shaanxi Vocational and Technical College. Guo Wen. 2010 (28). Discussion on the integration of solar energy and building technology for civil buildings.http://www.doc88.com/p-1446558007168. html.

2. Journal of Taiyuan University (Natural Science Edition). Wang Ying. 2016 (03). Research on the application of solar hot water in high-rise residential buildings in North China.

http://www.cnki.com.cn/Article/CJFDTOTAL-TYJY 201603003 .htm.

3. Inner Mongolia Science and Technology and Economy. Zhao Kaiwen. 2016(15). Advantages of applying solar energy in intelligent building systems. https://mall.cnki.net/magazine/article/NMKJ201615 053.htm.

4. Shanghai Electric Power. Ni Mingjiang. Luo

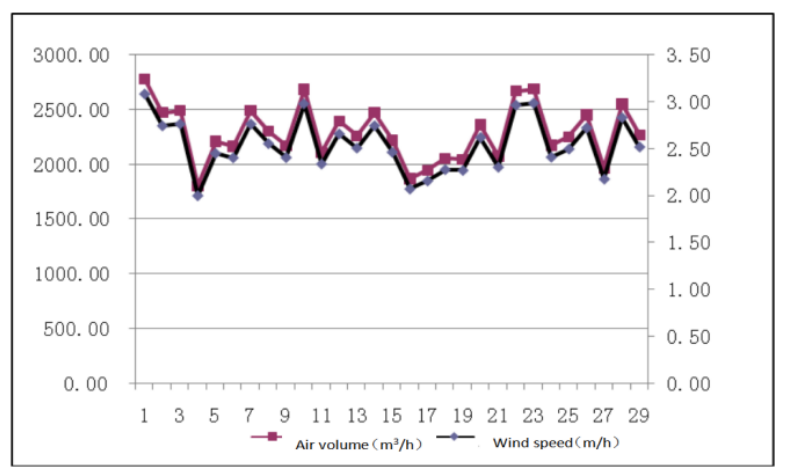

Figure 7: Exhaust air volume and wind speed

Zhongyang et al. 2009(1). Comprehensive Utilization of Solar, Thermal, Photovoltaic. https://doc.wendoc.com/b2287157cb56288343a71b3 6b.html.

5. Beijing Solar Energy Research Institute Co., Ltd. Zhu Dunzhi, Liu Jun, Lu Chao. 2015.8 Solar heating technology in the construction of new rural areas. https://max.book118.com/html/2015/0806/22685759 .shtm. 